\title{
A CASE OF MORQUIO'S DISEASE
}

\author{
BY
}

\author{
T. CRAWFORD, B.Sc., M.B., Сн.B.
}

From the Department of Paediatrics, Glasgow University, and the Royal Hospital for Sick Children, Glasgow.

In 1929 Morquio of Montevideo described two children, brother and sister, with curious skeletal deformities. To this he added in 1935 the description of two other children of the same family with similar deformities. Since 1929 reports of nine families have appeared in each of which two or more children have been affected in the same way (Ruggles, 1931; Barnett, 1933; Coward and Nemir, 1933 ; Davis and Currier, 1934 ; Valentin, 1930 ; Brown, 1933 ; Giraud and Bert, 1935 ; Summerfeldt and Brown, 1936). In addition six nonfamilial cases have been reported by Ruggles (1931), Meyer and Brenneman (1932), Sainz de los Terreros (1934), Freeman (1938) and Guerin and Lachapèle (1938).

The condition has been generally accepted as a disease sui generis and as only thirty cases have been recorded-only six of them non-familial-it has been thought worth while to add a report of another isolated case.

\section{Case Report}

The patient, a boy nine years of age, was brought to hospital because of a leg injury. This proved to be of quite a trivial nature and he was admitted to medical wards for investigation of the obvious skeletal deformity which he presented.

Family history.-No consanguinity of the parents can be traced. The patient's mother is a small woman (height 4 feet 9 inches), but she appears to be well proportioned and there is no evidence of skeletal deformity. The boy is the sixth in a family of eight children, of whom three have died (from a birth injury, a burn, and meningitis respectively) ; another suffers from epileptic fits. None of the family has been dwarfed or deformed in any way.

Patient's history.-The child was born at full time by an instrumental delivery. At birth he appeared normal and weighed eight pounds. He was breast fed for four months but subsequently was bottle fed till the age of fifteen months when mixed feeding was instituted. No additional vitamin or mineral preparations were given.

The first teeth were cut at the age of eleven months and talking began at one year. Walking was beginning at the age of one year and nine months when he was operated on for an inguinal hernia. Shortly after this he fell and fractured his left leg, and further attempts at walking were delayed until he was two-and-a-half years old. Additional leg fractures occurred at four years, six 
years and seven years of age, all necessitating long periods in bed, and the injury with which he was finally seen proved on x-ray examination to be yet another fracture of the leg which in this instance was only partial.

His walking is still slow and unsteady and he falls frequently. From the time he first began to walk his back has been noticed to be growing increasingly curved. His behaviour has always been normal.

General examination.-The boy's general appearance is illustrated in fig. 1 and fig. 2, and his measurements and weight are compared with normal values for a boy nine years of age in table 1 .

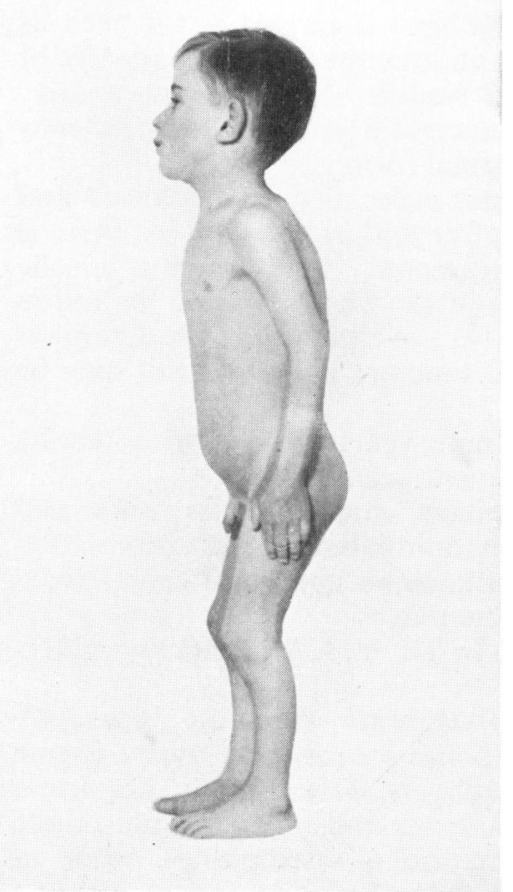

FIG. 1.-Lateral view of the patient.

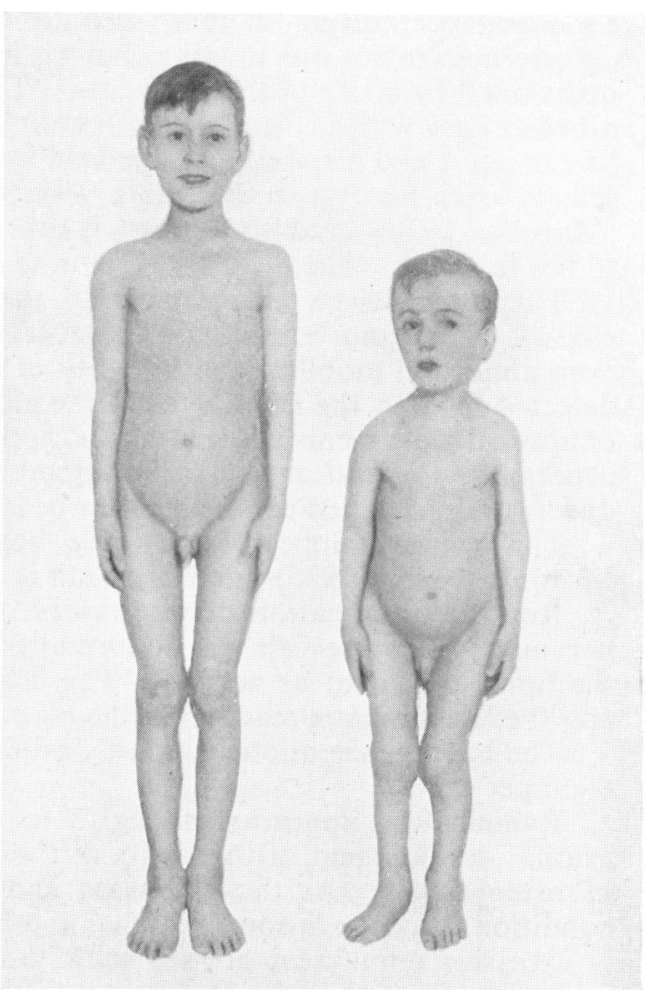

FIG. 2.-The patient with a normal boy of the same age.

TABLE 1

\begin{tabular}{|c|c|c|c|c|c|c|}
\hline & & & & & PATIENT & NORMAL \\
\hline $\begin{array}{l}\text { Weight . . } \\
\text { Height . . } \\
\text { Head circumference } \\
\text { Chest circumference } \\
\text { Sitting height . . } \\
\text { Upper limb length } \\
\text { Lower limb length }\end{array}$ & $\begin{array}{l}\cdots \\
\cdots \\
\cdots \\
\cdots \\
\cdots \\
\cdots \\
\cdots\end{array}$ & $\begin{array}{l}\cdots \\
\cdots \\
\cdots \\
\cdots \\
\cdots \\
\cdots\end{array}$ & $\begin{array}{l}\cdots \\
\cdots \\
\cdots \\
\cdots \\
\cdots \\
\cdots\end{array}$ & $\begin{array}{l}\cdots \\
\cdots \\
\cdots \\
\cdots \\
\cdots \\
\cdots\end{array}$ & $\begin{array}{l}18.6 \mathrm{kgm} . \\
103 \mathrm{~cm} . \\
53 \mathrm{~cm} . \\
60 \mathrm{~cm} . \\
58 \mathrm{~cm} \\
47 \mathrm{~cm} . \\
49 \mathrm{~cm} .\end{array}$ & $\begin{array}{l}26 \cdot 6 \mathrm{kgm} . \\
127 \mathrm{~cm} . \\
53 \mathrm{~cm} . \\
64 \mathrm{~cm} . \\
72 \mathrm{~cm} . \\
55 \mathrm{~cm} . \\
64 \mathrm{~cm} .\end{array}$ \\
\hline
\end{tabular}

From this it will be seen that the stunting of growth involves the lower limbs and the trunk to an approximately equal extent. 
The most striking abnormalities are in the spine and the thorax. The spine shows a severe though gradual kyphosis affecting the dorsal and upper lumbar regions. This deformity is quite fixed and no spinal movements of these parts are possible. Cervical movements are present but limited. The thorax displays a marked pigeon-breast deformity ; the sternum is pushed forward and the antero-posterior diameter of the chest is greatly increased while its lateral diameter is diminished. There is no beading of the ribs or other evidence of rickets. The lower costal margins descend to the iliac crests and the relatively long arms bring the finger-tips almost down to the level of the knees. The general appearance is reminiscent of a case of Paget's disease in miniature. In the standing position there is seen to be knock-knee and flat-foot. These deformities are not due to bony changes but to abnormal mobility of the joints, occasioned by laxity of the ligaments. The gait is characteristic ; he walks on a broad base with his trunk bent forward. His head is carried as far back as he can get it and his arms are also held back in an attempt to keep his centre of gravity over his feet. There is a pronounced waddle-' comme un canard' (Morquio, 1929) - and his progress is slow and uncertain, with a strong tendency to fall forward. The head appears to be of normal form and size.

There is obvious enlargement of the joints, especially at the knees and elbows. Joint movements are, however, quite free and in some places there is even abnormal mobility due to laxity of the ligaments. Joint crepitus can be detected in both the shoulder and the elbow joints. There is some limitation of upward movements of the arms due apparently to overgrowth of the acromion processes. General muscular development and tone are poor, but this may be due to the prolonged confinement to bed.

The genitalia appear large for a boy of nine years-a feature noted by Morquio (case 1, 1935) - and priapism is a frequent occurrence.

Routine examination of respiratory, alimentary, cardiovascular, renal and nervous systems reveals no abnormality. On ophthalmoscopic examination the fundi appear to be normal. The urine contains no abnormal constituents and the Wassermann reaction of the blood is negative.

The intelligence quotient (kindly estimated by Dr. V. J. M. Stark) is eightyeight per cent.

Radiological appearances (fig. 3 to 6).-Skiagrams show an apparently normal development of the shafts of the long bones except for a severe degree of osteoporosis. At the epiphyses and metaphyses, however, an abnormal condition is seen ; in some regions, notably the lower ends of the humeri, there is excessive epiphyseal growth with the formation of osteophytes, while at other situations (e.g. the carpus and the upper ends of the femora) ossification is delayed and distorted. Clear islets of cartilage, separated by irregular bony strands, can be seen persisting throughout the substance of the epiphyses. At the upper ends of the femora the formation of the heads and trochanters is defective ; whilst the carpus, though showing the normal number of ossifying centres, is poorly developed for a boy nine years of age. Skiagrams of a lateral view of the spine show that the vertebral bodies are flattened vertically, a condition which has been described as 'biscuit shaped' and to which the term 'platyspondyly' has been applied. The intervertebral discs are as wide as or wider than the neighbouring vertebral bodies. In an antero-posterior view the epiphyses forming the lateral and articular processes are seen to be irregularly formed and it is presumably the interlocking of these processes which accounts for the immobility of the spine. Skiagrams of the skull show no abnormality.

Biochemical findings.-During the boy's stay in hospital the following estimations were made. Serum calcium $12.1 \mathrm{mgm}$. per cent. ; inorganic blood phosphorus $3.8 \mathrm{mgm}$. per cent. ; plasma phosphatase 18.8 units (maximum normal 12 units) ; blood non-protein nitrogen $40 \mathrm{mgm}$. per cent. ; standard 


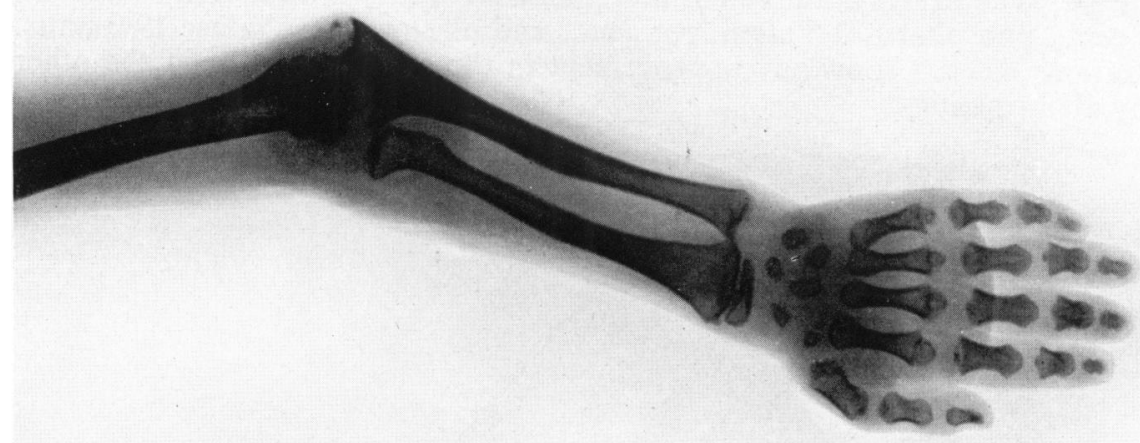

Fig. 3.-Skiagram of arm and hand showing irregularity of metaphysis and epiphyses, delayed ossification and osteophytes.
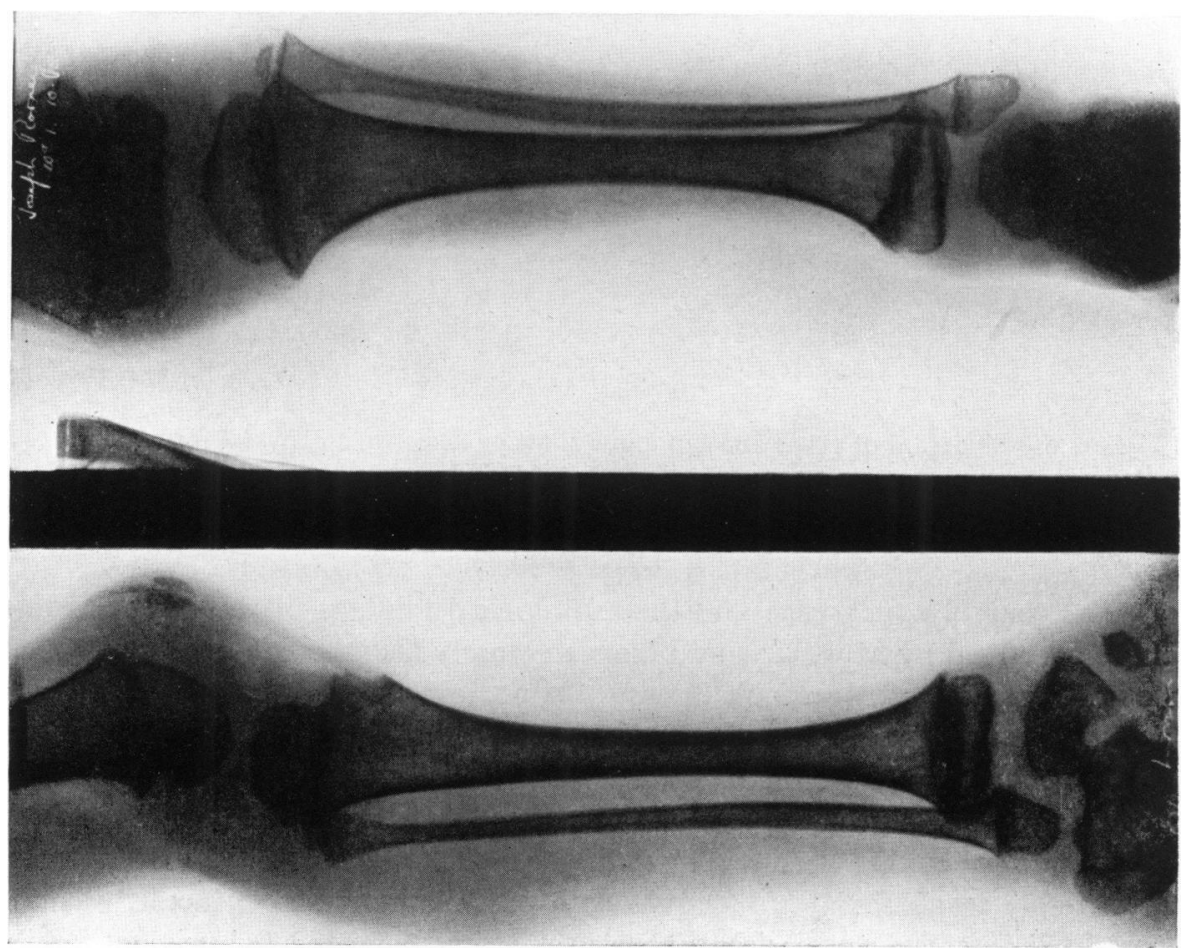

Fig. 4.-Skiagram of knee and ankle joints showing osteoporosis, osteophyte formation and irregular ossification. 
urea clearance 90 per cent. ; urea concentration after $15 \mathrm{gm}$. urea 3.3 per cent. ; blood cholesterol $105 \cdot 7 \mathrm{mgm}$. per cent.

Subsequently thirty minims of adexolin (ten thousand units of vitamin D) were administered daily for one month without change in the biochemical findings. The figures at the end of that period were : serum calcium $12 \cdot 4 \mathrm{mgm}$. per cent., phosphorus $3.6 \mathrm{mgm}$. per cent., and plasma phosphatase 19.0 units. Skiagrams did not show any improvement in the osteoporosis or in the other bony abnormalities.

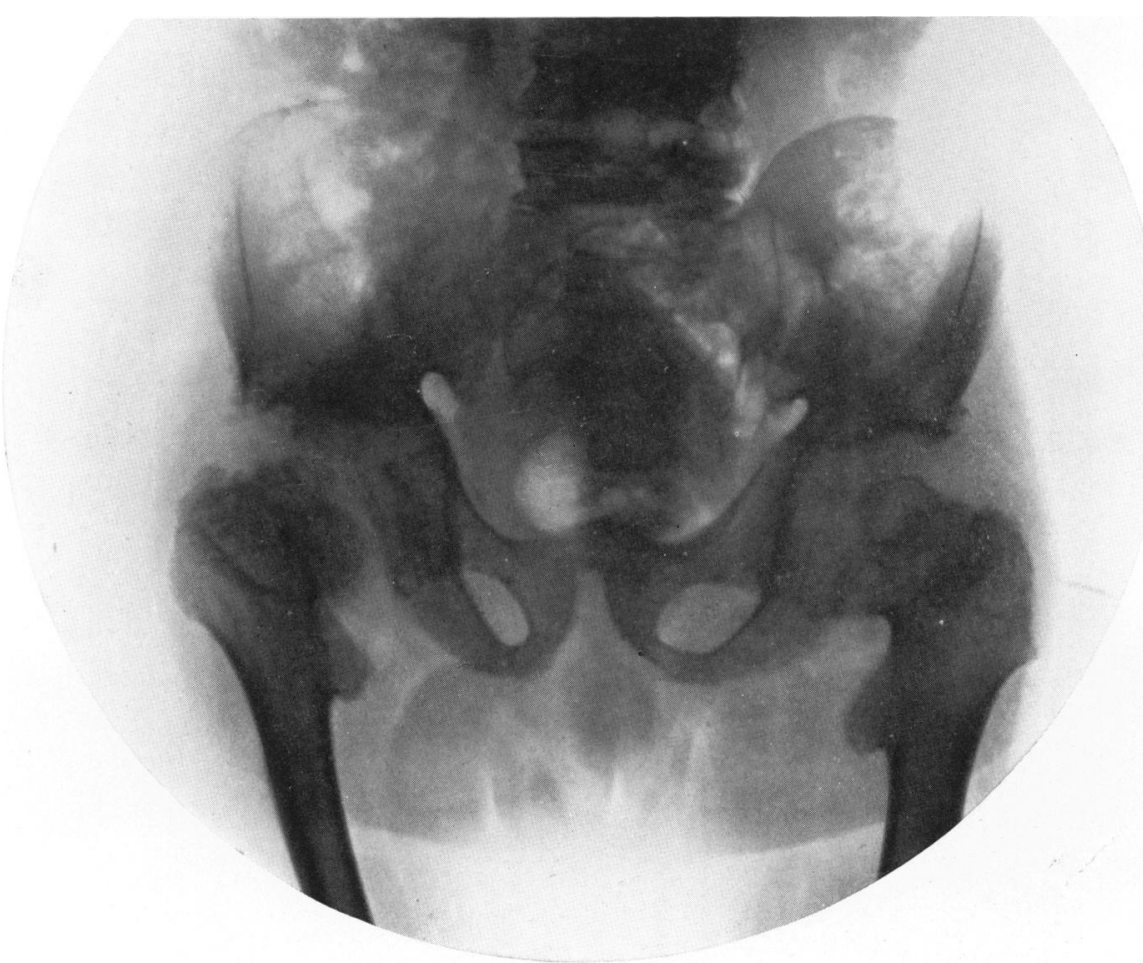

FIG. 5.-Skiagram of pelvis and hip joints showing defective epiphyseal formation at upper ends of femora.

\section{Discussion}

The general appearance and the radiological findings of the boy resemble those described by Morquio and others so closely that there is little doubt that he is an example of Morquio's disease ; bone, joint and postural changes show a striking resemblance to the illustrations in Morquio's publications. Morquio's disease may readily be distinguished from other types of dwarfism such as achondroplasia, gargoylism and late rickets by the general aspect of the patient and the bony changes as shown by radiography. Consanguinity of the parents, so strongly emphasized by Morquio as a possible aetiological factor, was not present in this case and indeed has been noted in none but the original family which Morquio described. In Morquio's first two cases (1929) low values were found for the serum calcium ( 5.2 and $4.5 \mathrm{mgm}$. per cent.) but in the two cases 


\section{A CASE OF MORQUIO'S DISEASE}

he described later and in those reported by subsequent authors normal values were found. In the present case, though the serum calcium and phosphorus

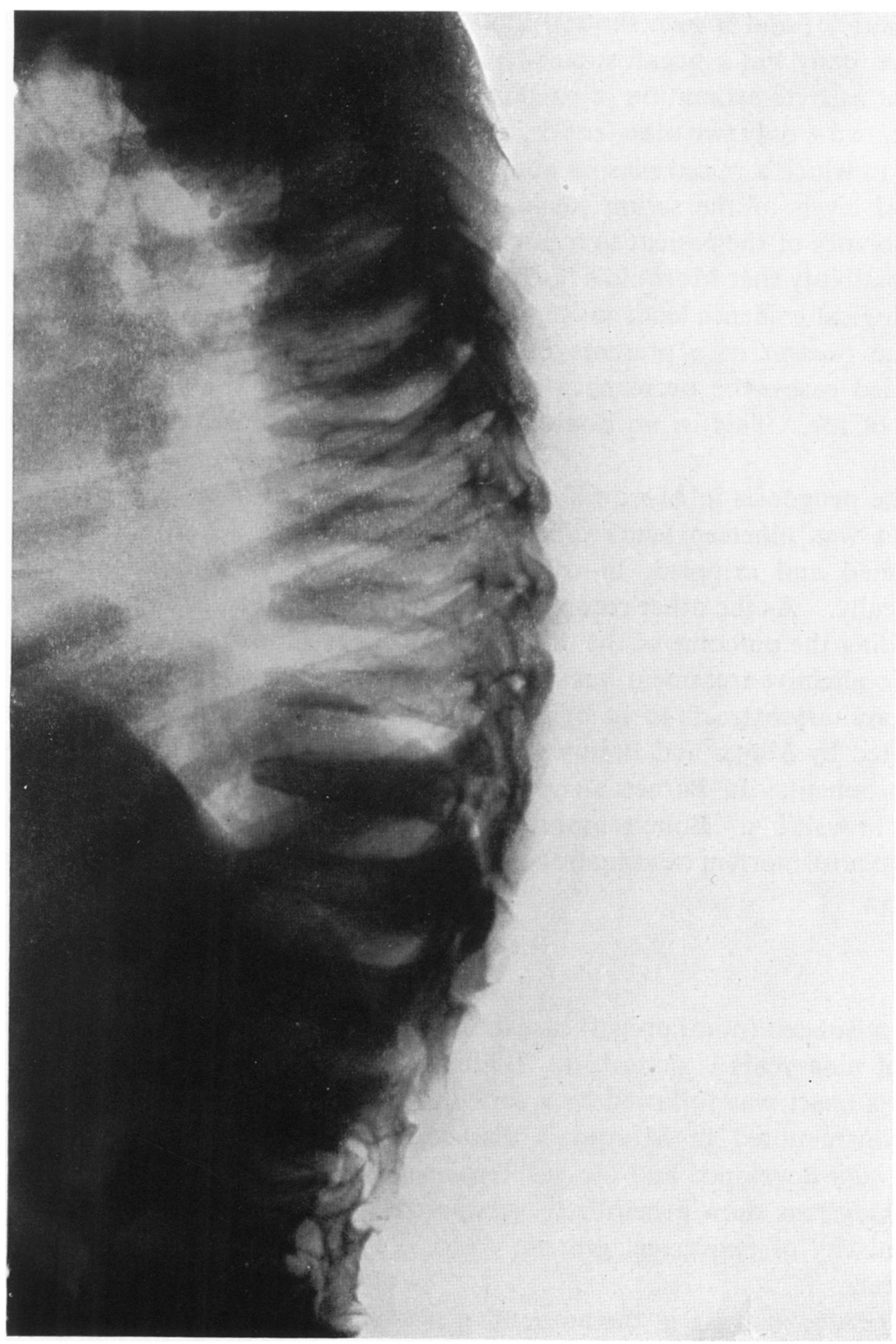

FIG. 6.-Skiagram of lateral view of spine showing flattened wedge-shaped vertebrae with widened intervertebral spaces-platyspondyly.

values were normal, the plasma phosphatase was increased to 19 units (maximum normal 12 units) and this value persisted in spite of heavy dosage with vitamin D. Phosphatase estimations have been made in only two previous cases of 
Morquio's disease (Summerfeldt and Brown, 1936). The values found were 12.6 and 19.2 units but the authors make no comment beyond the statement that the biochemical findings were all within normal limits. The patients of Summerfeldt and Brown showed a positive calcium balance on one gramme of calcium daily but a negative balance on one-tenth of a gramme daily. In the present case no estimation of calcium retention was made.

There are only two other conditions, Paget's disease of bone and healing fractures, in which a raised plasma phosphatase value is found in conjunction with normal levels of the serum calcium and phosphorus. Although the general resemblance of the patient to a case of Paget's disease already mentioned, raises the possibility that Morquio's disease may be a juvenile form of Paget's disease, radiological evidence lends no support to this attractive speculation.

The present case presents one feature noted in none of the previously rezorded cases, the occurrence of pathological fractures during the first few years of life. This is, no doubt, an expression of the osteoporotic condition present.

The prognosis in Morquio's disease is as yet unknown. Morquio's oldest patient was nineteen years of age when reported in 1935. Though grossly deformed and crippled, in other respects he was well both mentally and physically. As the other recorded cases are too young to draw any conclusions regarding the outcome of the disease the prognosis must remain in doubt.

No effective treatment has been discovered. Ruggles (1931) found thyroid and pituitary extracts to be of no value and in the present case, as in the one reported by Meyer and Brenneman (1932), vitamin D preparations caused no improvement. In Barnett's case (1933) osteotomy resulted in some improvement in walking. Bone removed at the operation was histologically normal.

No post-mortem examination has as yet been reported in a case of Morquio's disease.

\section{Summary}

An isolated (non-familial) case of Morquio's disease in a boy first seen at the age of nine years is described. Walking began at one year and nine months and its onset was followed by a series of pathological fractures (a feature not previously noted in Morquio's disease). Increasing kyphosis and thoracic deformity developed and the gait remained unsteady.

Skiagrams show generalized osteoporosis, marked platyspondyly, and great irregularity of epiphyseal growth. The skull is not affected and mentality is normal.

There is increase in the amount of plasma phosphatase in association with normal values for the serum calcium and phosphorus. The phosphatase and the radiological appearances were uninfluenced by the administration of large doses of vitamin D.

Thanks are due to Professor G. B. Fleming for permission to publish this case and for his help in the preparation of this paper, and to the staffs of the biochemical and radiological departments of the hospital for their aid in the 


\section{A CASE OF MORQUIO'S DISEASE}

investigations. Thanks are also due to the Medical Research Council for defraying part of the expenses.

\section{REFERENCES}

Brown, D. O. (1933). Med. J. Austral., 1, 598.

Barnett, E. J. (1933). J. Pediat., 2, 651.

Coward, N. R., and Nemir, R. L. (1933). Amer. J. Dis. Child., 46, 213.

Davis, D. B., and Currier, F. P. (1934). J. Amer. med. Ass., 102, 2173.

Freeman, J. (1938). Amer. J. Dis. Child., 55, 343.

Giraud, G., and Bert, J. M. (1935). Rev. neurol., 63, 845.

Guerin, R., and Lachapèle, A. P. (1938). Rev. Orthopéd., 25, 23.

Meyer, H. F., and Brenneman, J. (1932). Amer. J. Dis. Child., 43, 123.

Morquio, L. (1929). Arch. Méd. Enf., 32, 129.

- (1935). Arch. Méd. Enf., 38, 1.

Ruggles, H. E. (1931). Amer. J. Roentgen., 25, 91.

Sainz de los Terreros, C. (1934). Arch. españ. Pediat., 18, 412.

Summerfeldt, P., and Brown, A. (1936). Arch. Dis. Childh., 11, 221.

Valentin, B. (1930). Z Zbl. Chir., 57, 2038. 